http://jmscr.igmpublication.org/home/ ISSN (e)-2347-176x ISSN (p) 2455-0450

crossref DOI: https://dx.doi.org/10.18535/jmscr/v8i1.46

\title{
Study of Lipid Profile in Patients with Diabetes Mellitus
}

\author{
Authors \\ Soni Talreja ${ }^{1}$, Md. Israrul Haque ${ }^{2}$ \\ ${ }^{1}$ Assistant Professor, Department of General Medicine, IGIMS, Patna \\ ${ }^{2}$ Assistant Professor, Department of General Medicine, NSMCH, Bihta, Patna
}

\begin{abstract}
Diabetes Mellitus is the most common metabolic disorder affecting people all over the world. It has been known to be associated with lipid disorders and cardiovascular complications. ${ }^{[1]}$ Dyslipidemia is one of the major cardiovascular disease (CVD) risk factors and plays an important role in the progress of atherosclerosis, the underlying pathology of CVD. ${ }^{[2]}$

The aim of this study is to assess the lipaemic changes in diabetes mellitus patients attending opd and indoors.
\end{abstract}

\section{Introduction}

Diabetes mellitus (DM) is the most common metabolic disorder affecting the people worldwide. Even though diabetes has been known since antiquity, only in the last few decades new discoveries have provided great hopes to minimize morbidity and mortality. It is estimated that for one diagnosed diabetes there is undetected diabetes. The diabetic ketoacidosis was major fatal complication of diabetes has virtually come down with advent of insulin.

However, the vascular complications have remained same and they have replaced diabetic ketoacidosis as the frequent cause death in diabetes. Dyslipidemia is commonly seen diabetes. Type $2 \mathrm{DM}$ is one of the most common secondary causes of hyperlipidemia. The relationship between hyperlipidemia and vascular complication of diabetes has long been of interest because both tend to occur with greater frequency in Type 2 DM. Insulin resistance and obesity combine to cause dyslipidemia and hyperglycemia and hyperlipidemia have additive cardiovascular risk. It is recommended that patients with DM should be treated as if they already have coronary artery disease. Hence identification, critical evaluation, and follow-up of serum lipid profile in Type 2 DM continue to be important. ${ }^{1-4}$

\section{Methods}

The present study was a cross sectional study conducted by the department of General Medicine at IGIMS, Patna and NSMCH, Bihta Patna, from August 2019 to October 2019 on 50 diabetic patients in which 30 were males and 20 were females. All the patients were selected randomly in both outpatient and inpatient wards. All the patients were explained about the study and the informed consent was obtained. Age, duration of diabetes, height, weight, and body mass index were recorded in all the patients.

\section{Inclusion Criteria}

- Patients with type 2 diabetes mellitus with the duration of more than 4 years were 
included in the study.

\section{Exclusion Criteria}

- The patients with type 2 diabetes mellitus with conditions altering the lipid levels and the patients suffering from coronary artery disease (CAD), cerebrovascular accident (CVA), having past history of CAD or CVA and the patients already taking drugs for lipid lowering were excluded from the study.

\section{Statistical Analysis}

The mean and standard deviations were calculated for FBS, TC, triglycerides, HDL, and LDL in both males and females separately. The guidelines of national cholesterol education programmed (NCEP) adult treatment panel III (ATP III) were followed for the interpretation of serum lipid reference values. NCEP- ATPIII guidelines defines hypercholesterolemia as TC>200mg/dl, high LDL-C when value $>100 \mathrm{mg} / \mathrm{dl}$, hypertriglyceridemia as TAG $>150 \mathrm{mg} / \mathrm{dl}$ and low HDL-C when value is $<40 \mathrm{mg} / \mathrm{dl} .10$ Percentage wise variation in the incidence of dyslipidemia in the male and female diabetic patients was noted.

\section{Results}

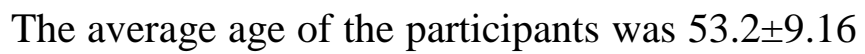
years. The average fasting blood glucose was noted as $172.28 \pm 42.62 \mathrm{mg} / \mathrm{dl}$. The average total cholesterol, triglycerides, LDL, HDL and VLDL were $\quad 200 \pm 42 \mathrm{mg} / \mathrm{dl}, \quad 169.62 \pm 89.79 \mathrm{mg} / \mathrm{dl}$, $132.45 \pm 36.38 \mathrm{mg} / \mathrm{dl}, \quad 39.1 \pm 16.6 \mathrm{mg} / \mathrm{dl} \quad$ and $35.85 \pm 17.09 \mathrm{mg} / \mathrm{dl}$ respectively. In the present study all the participants were having dyslipidemia as one or two parameters of the lipid profile were outside the target recommended by the guidelines of national cholesterol education programmed. Out of 50 diabetic patients, 30 $(60 \%)$ were having hypercholesterolemia, 19 $(38 \%)$ patients were having hypertriglyceridemia, $32(64 \%)$ patients were having increased LDL levels, and 41 (82\%) patients were having reduced HDL levels.

Out of 20 females, $16(69.5 \%)$ patients were having hypercholesterolemia,15 (52.1\%) patients were having hypertriglyceridemia,13 (65\%) patients were having increased LDL and 14 (70\%) patients were having reduced HDL. Out of 30 males, $22(73 \%)$ patients were having hypercholesterolemia, $12(40 \%)$ were having hypertriglyceridemia, 14 (46.6\%) patients were having high LDL levels and 13 (43.3\%) were having reduced HDL. Incidence was observed to be very high in female diabetic patients when compared to male diabetic patients.

These observations further confirm that patients with Type 2 Diabetes Mellitus have co-incidence of several lipid profile abnormalities. Dyslipidaemia could have an impact on the development of insulin resistance in Type2 Diabetes Mellitus. There might be some significant genetic association between development of insulin resistance and dyslipidaemia among Type 2 Diabetes patients. ${ }^{[3]}$

\section{Conclusion}

The present study on the Type 2 diabetic patients suggested that common lipid abnormalities in diabetes induced dyslipidaemia are hypercholesterolemia, hypertriglyceridemia and elevated LDL cholesterol.

Results suggest a high prevalence of dyslipidaemia which might be playing a major role in the development of cardiovascular diseases and cerebrovascular accidents among the patients of Type 2 Diabetes Mellitus.

The optimal care for the diabetic patient should therefore include routine monitoring of blood glucose and serum lipid profile. Efforts to achieve lifestyle changes such as weight reduction physical exercise and abstinence from smoking should be encouraged and initiated first and then followed by medication with lipid lowering drugs prescribed in evidence based necessary conditions.

The optimum treatment with proper anti-diabetic drugs to obtain a fair glycaemic control should go concomitantly with lipid lowering drugs, along with dietary precautions. 


\section{References}

1. Zargar AH, Wani AI, Masoodi SR, Laway BA, Bashir MI. Mortality in diabetes mellitus-data from a developing region of the world. Diab Res Clinic Pract. 1999;43(1):67-4.

2. Parkhad S, Palve S. Early diagnosis of neuropathy in diabetic patients using nerve conduction studies. National J Physiol Pharm Pharmacol. 2014;4(2):158.

3. Vittal V, Shankar V, Kutty K, Kumar SA. An interventional study of physical activity on $\mathrm{HbA} 1 \mathrm{C}$ and $\mathrm{VO} 2 \mathrm{max}$ in type 2 diabetes mellitus. Indian $\mathrm{J}$ Physiol Pharmacol. 2016;60(1):76-81.

4. Anjana RM, Pradeepa R, Deepa M, Datta M, Sudha V, Unnikrishnan R, et al. Prevalence of diabetes and prediabetes (impaired fasting glucose and/or impaired glucose tolerance) in urban and rural India: Phase I results of the Indian council of medical research-India diabetes study. Diabetol. 2011;54(12):3022-7.

5. American diabetes association - Position statement. Management of Dydlipidamia in Adults with Diabetes. Diabetes Care, 1998; 21: 179-82.

6. A study of lipid profile in Type 2 Diabetic Punjabi Population - Singh and Kumar, Journal of Exercise Science and Physiotherapy, 2012; 8(1): 7-10. Lipid profile levels in Type 2 Diabetes Mellitus in tribal population of Adilabad in Andhra Pradesh, India, V. Siva Prabodh et al, Journal of Clinical and Diagnostic research, 2012. 